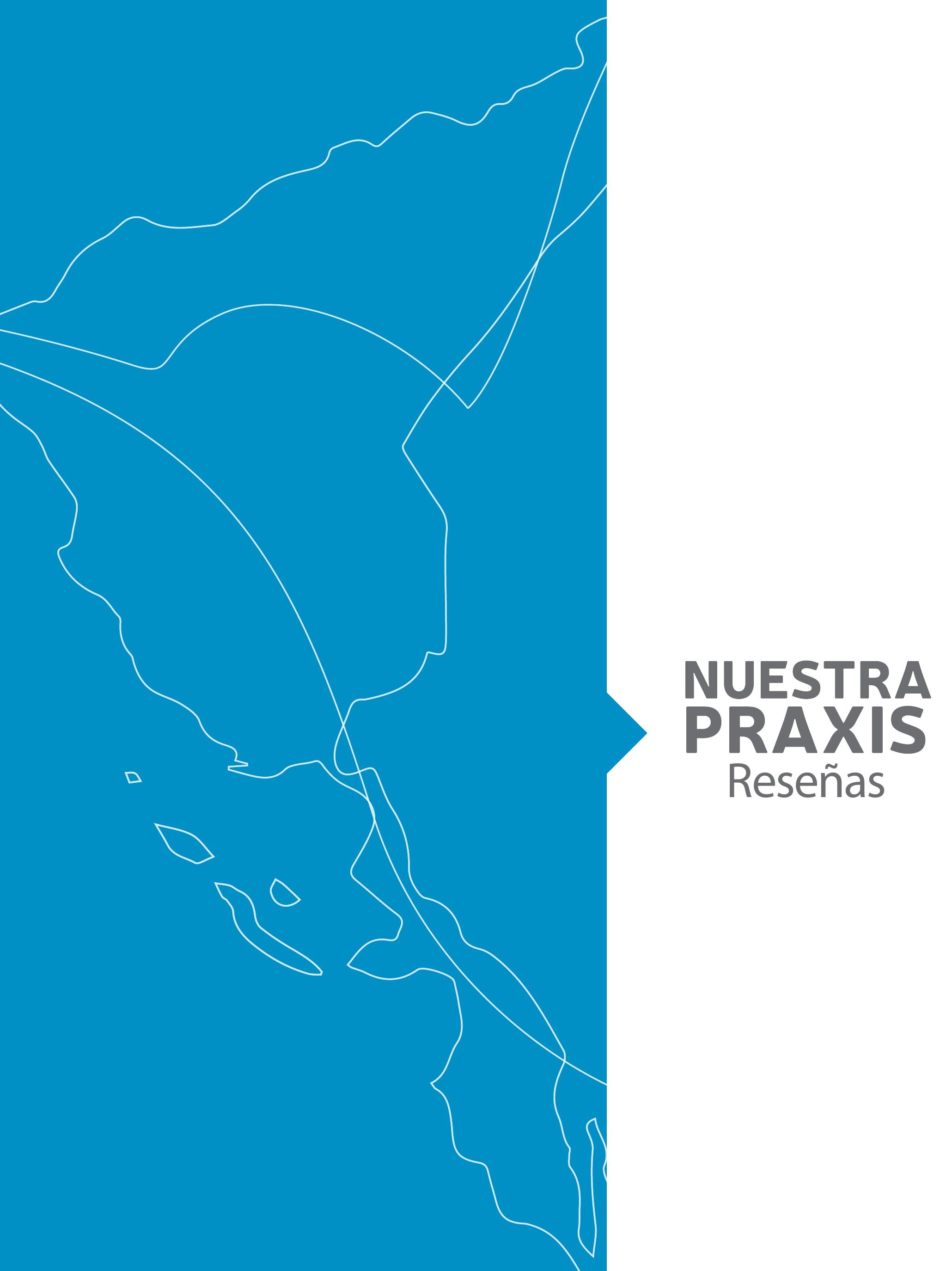




\section{RESEÑA: \\ EL DISCURSO CRÍTICO DE MARX \\ DE BOLÍVAR ECHEVERRÍA}

Profesora en la Facultad de Filosofía y Letras de la Universidad Nacional Autónoma de México. Correo electrónico: dianafuentes.fil@gmail.com
Autor: Diana Fuentes
Esta obra está bajo una licencia de Creative Commons ReconocimientoNoComercial 4.0 Internacional. https:// creativecommons.org/licenses/by-nc$\mathrm{sa} / 4.0 /$
$B$ olivar Echeverría se ha convertido en uno de los teóricos marxistas más destacados de las últimas décadas. Su obra es ya uno de los referentes obligados del pensamiento latinoamericano, al ser uno de los lectores más originales y penetrantes de la obra de Karl Marx de los últimos tiempos, asi como por su fina interpretación de los rasgos de los modos de vida cultural que han emergido como estrategias de sobrevivencia ante la dinámica destructiva y desintegradora del capitalismo.

La de Echeverría es una obra que se bifurca por caminos que lo llevan a la reflexión sobre los principios técnicos y las elecciones civilizatorias que dieron origen a la modernidad y a su unión con el capitalismo, hasta el tipo de estrategia, ethos, que se produjo en América Latina como efecto de su peculiar manera de resistir a la devastación imperial. Para todo ello, Echeverría toma como sustento nutricio la descripción de Marx sobre la reproducción social en general y sobre la reproducción social capitalista, bajo la perspectiva de la centralidad de la contradicción entre la forma del valor de uso y la forma de valor. Es el discurso crítico de Marx, como él mismo lo llama, el horizonte desde el cual analiza los rasgos de la modernidad y lugar desde donde construye su propio pensamiento.

Se trata de ese Marx del que en sus cátedras en la Universidad Nacional Autónoma de México (UNAM) decía era el gran desconocido, puesto que detrás del ícono revolucionario, cuyo nombre aún hace temblar a los guardianes del estatus quo y cuya imagen se convirtió en estandarte e incluso en insignia ideológica, en verdad, se oculta hasta la fecha un profundo temor y 
desprecio de parte sus críticos, tanto como una amplia ignorancia sobre su pensamiento entre propios y extraños. Así lo demuestra el que su obra cumbre, El capital, ese proyecto que se convertiría en un "todo artístico", resulte aún tan ajena. Y es, precisamente, al Marx de El capital a quien Bolívar Echeverría pretendió descifrar y de quien abreva aquello que le permitió producir una interpretación de la modernidad, de su cultura y de sus alcances y límites.

Ése es el objetivo principal de algunos de los de los ensayos que se recogen en su primer libro El discurso crítico de Marx que fue publicado en 1984 y que no había vuelto a las imprentas hasta la reciente edición del Fondo de Cultura Económica y de la editorial Ítaca, dirigida por David Moreno, también responsable de esta edición. A diferencia de la edición original, en esta ocasión, el libro recoge los ensayos de la versión anterior del texto, colocándolos en un primer apartado, más una segunda parte, completamente nueva, en la que se integran dos textos que, si bien ya habían sido publicados en una revista y en un cuadernillo, eran muy difíciles de localizar, por esto es que a pesar de tratarse de textos redactados con posterioridad a los otros, corresponden a un mismo interés general y a una época de la producción del autor que los hace empatar con el sentido general de la obra. De este modo, esta nueva edición actualiza la obra del autor y otorga nuevas claves de su producción teórica.

Sobre El discurso crítico de Marx, se podría decir, con algunas salvedades, que no sólo es la primer obra de Echeverría, sino que es, en verdad, la obra fundamental de su pensamiento, en el mismo sentido en el que el sustantivo Grund del alemán, que remite al fundamento y al principio activo, sirvió a los editores del Instituto Marx-Engels-Lenin en 1939-41 para titular los manuscritos preparatorios de Marx a El capital como Grundrisse. Es decir, se trata de los cimientos, en este caso, del discurso, $\mathrm{y}$, al mismo tiempo, de aquello que funciona como principio agente y articulador del mismo. Dicho de otro modo, en El discurso crítico de Marx, hallamos los ejes cardinales de la lectura de Echeverría sobre la obra del treverino, así como los principios desde los cuales fundamenta su particular insistencia en la centralidad de la contradicción entre valor de uso y valor, y su original contribución a la interpretación del proceso de reproducción social derivada de la relación metabólica entre el ser humano y la naturaleza como un proceso que al mismo tiempo reproduce al ser humano en un plano semiótico, es decir, en el plano en el que da y encuentra sentido a su mundo.

De esta manera, los ensayos que integran la actual versión de El discurso crítico de Marx muestran la madurez del autor desde esa temprana época y revelan algunas de las influencias fundamentales de su pensamiento. Evidentemente, en primer orden la del propio Marx, a quien Echeverría suponía debía esclarecer en términos del gran proyecto de interpretación, explicación y comprensión del modo de producción capitalista como se muestra en El capital. Obra que, a pesar de ser inconclusa puesto que Marx murió antes de lograr concretar sus objetivos, contiene una perspectiva de totalidad sobre la manera en la que se produce y se reproduce la vida material en las sociedades contemporáneas. Es, la miradad de Marx, pensaría Echeverría, una suerte de gran angular del que sólo nos podemos apropiar al leer el texto desde una perspectiva integral, es decir, mostrando los distintos momentos de su análisis para comprender no sólo la lógica y los fundamentos epistémicos con los que trabaja, sino, sobre todo, para observar cómo es que construye un discurso que se pone como objetivo hacer una crítica radical de la realidad desde las contradicciones que el propio discurso es capaz de develar en ella. Por ello es que para Echeverría era tan relevante comprender $\mathrm{El}$ capital como una obra total, así como esclarecer las partes que lo integran y los distintos momentos argumentales en ella. En ese empeño se juega, en buena medida, su apuesta por comprender el discurso crítico como una forma de explicación de la realidad que de suyo o de forma intrínseca supone la posibilidad histórica de suvertir esa realidad y de darle un cause radicalmente distinto. 
Por esto es que, una buena parte, de El discurso crítico de Marx está dedicado al estudio del sentido del quehacer teórico de Marx, a la esquematización de los distintos momentos expositivos de El capital, a la comprensión de las contradicciones inherentes al sistema capitalista y sus efectos, y a ciertos debates derivados de algunas de las problemáticas relacionadas con el sentido político de la crítica y con sus posibilidades emancipatorias. Aspectos todos centrales para una lectura que prentenda hacer de la crítica de la economía política un proyecto abierto, capaz de atender y dar cuenta de los problemas contamporáneos. Es, por todo esto, un libro que cobra una importantísima actualidad ya que renueva la necesidad de una lectura profunda y creativa de la obra de Marx que ponga en cuestionamiento la presupuesta y tan aceptada inevitabilidad del hecho capitalista. 